\title{
The eye of the Barbary sheep or aoudad (Ammotragus lervia): Reference values for selected ophthalmic diagnostic tests, morphologic and biometric observations
}

\author{
G.A. Fornazari ${ }^{1}$, F. Montiani-Ferreira ${ }^{1, *}$, I.R. de Barros Filho ${ }^{1}$, A.T. Somma ${ }^{1}$ and B. Moore ${ }^{2}$ \\ ${ }^{1}$ Universidade Federal do Paraná, Programa de Pós-Graduação em Ciências Veterinárias, \\ Rua dos Funcionários 1540, 8035-050, Curitiba, PR. Brazil \\ ${ }^{2}$ Veterinary Specialty Hospital of San Diego, 10435 Sorrento Valley Road, San Diego, CA 92121, USA
}

\begin{abstract}
The purpose of this study was to describe the normal ocular anatomy and establish reference values for ophthalmic tests in the Barbary sheep or aoudad (Ammotragus lervia). Aoudad eyes are large and laterally positioned in the head with several specialized anatomic features attributed to evolutionary adaptations for grazing. Normal values for commonly used ophthalmic tests were established, Schirmer tear test (STT) - $27.22 \pm 3.6 \mathrm{~mm} / \mathrm{min}$; Predominant ocular surface bacterial microbiota - Staphylococcus sp.; Corneal esthesiometry- $1.3 \pm 0.4 \mathrm{~cm}$; Intraocular pressure by rebound tonometry- $19.47 \pm 3.9 \mathrm{mmHg}$; Corneal thickness- $630.07 \pm 20.67 \mu \mathrm{m}$, B-mode ultrasonography of the globe- axial eye globe length $29.94 \pm 0.96 \mathrm{~mm}$, anterior chamber depth $5.03 \pm 0.17 \mathrm{~mm}$, lens thickness $9.4 \pm 0.33 \mathrm{~mm}$, vitreous chamber depth $14.1 \pm 0.53 \mathrm{~mm}$; Corneal diameter- horizontal corneal diameter $25.05 \pm 2.18 \mathrm{~mm}$, vertical corneal diameter $17.95 \pm 1.68 \mathrm{~mm}$; Horizontal palpebral fissure length- $34.8 \pm 3.12 \mathrm{~mm}$. Knowledge of these normal anatomic variations, biometric findings and normal parameters for ocular diagnostic tests may assist veterinary ophthalmologists in the diagnosis of ocular diseases in this and other similar species.
\end{abstract}

Keywords: Barbary sheep, Biometry, Ocular parameters, Wild caprid.

\section{Introduction}

The Barbary sheep or aoudad (Ammotragus lervia) is a species of wild caprid (goat-antelope), whose natural habitat includes northern Africa in Algeria, Tunisia, northern Chad, Egypt, Libya, northern Mali, Mauritania, Morocco, Niger and Sudan (west of the Nile, and in the Red Sea Hills east of the Nile). It is also known as waddan, arui, and arruis (Cassinello, 1998; Wacher et al., 2002; Cassinello et al., 2004). The binomial name Ammotragus lervia derives from the Greek ammos "sand", referring to the sandcoloured coat) and tragos ("goat"). The species name lervia derives from the wild sheep of northern Africa (Cassinello, 1998; Wacher et al., 2002). In its native distribution in northern Africa the aoudad was classified as a "vulnerable" species by the 2012 Red List of the International Union of Conservation of Nature (IUCN) due to natural habitat loss and poaching (Alados and Shackleton, 1997; Hilton-Taylor, 2000; Cassinello et al., 2008). It has, however, been successfully introduced to North America, Europe and elsewhere primarily for trophy-hunting purposes. These introduced populations contain a large number of individuals and are free-ranging, commonly competing with the native mammals for resources (Cassinello et al., 2008). The aoudad is a stocky, heavily built wild ruminant, with short legs and a rather long skull (Kingdon, 1997;
Stuart and Stuart, 1997). Both sexes have horns that sweep backwards and outwards in an arch; those of the male are much thicker and reach up to $50 \mathrm{~cm}$. Aoudads' weight can vary from 40 to $140 \mathrm{~kg}$. Males also differ from females by their significantly heavier weight, up to twice that of females (Kingdon, 1997), and the notably longer curtain of hair that hangs from the throat, chest and upper part of the forelegs (Kingdon, 1997; Stuart and Stuart, 1997; Cassinello, 1998). The coat is woolly during the winter, but moults to a finer, sleek coat for the hot summer months. It has a sandybrown color, darkening with age, with a slightly lighter underbelly and a darker line along the back (Kingdon, 1997; Stuart and Stuart, 1997). The eyes of the aoudad are bright and apparently large in relation to its body size, more consistent with a cervid- or antelocaprid-like morphology than a caprid one. Concerning aoudads in the scientific literature, hormonal parameters and studies about applied reproductive techniques have been published (Hamon and Heap, 1990; Crenshaw et al., 2000; Abáigar et al., 2012; Santiago-Moreno et al., 2013). Additionally, genetic studies (McLelland et al., 2005; Manca et al., 2006; Mereu et al., 2008), epidemiologic surveys and reports of specific infectious diseases (Yeruham et al., 2004; Candela et al., 2009; Pirastru et al., 2009; Portas et al., 2009; Münster et al., 2013; Morikawa et al., 2014) and parasites (Pence and 
Gray, 1981; Cho et al., 2006; Mayo et al., 2013) were investigated. An additional case report of pemphigus foliaceus has been published in this species (Brenner et al., 2009). However, no ophthalmic investigations or even reports of ocular diseases on this species were available, possibly because baseline values for diagnostic tests have not yet been established for aoudads. Knowledge of baseline values is essential for both making appropriate diagnoses and properly treating ocular diseases in zoo and exotic animals. Important parameters to be established in wild animals include tear production (Schirmer tear test, STT) and intraocular pressure (IOP), echobiometric findings as well as normal conjunctival bacterial microbiota (Prado et al., 2005; Kudirkiene et al., 2006; Montiani-Ferreira et al., 2006, 2008b; Martins et al., 2007; Wang et al., 2008; Ribeiro et al., 2009; Lima et al., 2010; Ghaffari et al., 2012). These normal ophthalmic parameters in domestic, exotic and zoo animals become important references for the veterinary clinician and other researchers once published. The purpose of this study was to describe normal ophthalmic parameters in aoudads, including morphological features, biometry of anatomical structures, corneal ultrasonic pachymetry, globe echobiometry, tear production (Schirmer's tear test, STT), intraocular pressure (IOP), corneal sensitivity, bacterial conjunctival microbiota, and fundus photography.

\section{Materials and Methods}

All ophthalmic procedures using live aoudads were conducted in accordance with UFPR's Animal Use Committee and with the ARVO Statement for the Use of Animals in Ophthalmic and Vision Research. Eighteen adult captive aoudads (11 males and 7 females) of different ages (varying from 1.5 to 7 years of age, mean $4 \pm 2.0$ years) belonging to Curitiba's Zoo (Zoológico de Curitiba), Curitiba-PR, Brazil $\left(25^{\circ} 25^{\prime} \mathrm{S}\right.$ and $\left.49^{\circ} 16^{\prime} \mathrm{W}\right)$ were captured for clinical evaluation as part of a health survey by the park authority (Fig. 1) during the winter of 2014 on three different occasions. A detailed ophthalmic evaluation including all the tests cited here was performed in this survey. Physical examinations, including a complete blood count panel, were performed before ocular examinations to exclude animals with indications of systemic disease. Aoudads with evidence of ocular or systemic diseases were excluded. Procedures and tests necessary to produce this work were split between the investigators. However, to avoid discrepancies related to inter-observer repeatability, the same person always performed the same ocular test on each occasion.

\section{Ophthalmic tests}

Clinical tests were performed while the aoudads were physically restrained by two experienced handlers using ropes, taking care to keep the animal comfortable. When the head was manually stabilized for taking measurements special attention was given to avoid applying pressure to the neck region with hands or ropes, to prevent iatrogenic alterations in IOP. The sequence of procedures performed in this study was, (i) ocular inspection (including photography), (ii) Schirmer tear test (STT), (iii) collection of material for bacterial culture analysis, (iv) corneal esthesiometry, (v) tonometry, (vi) central corneal thickness (CCT) measurement with an ultrasonic pachymeter, (vii) B-mode ultrasonography of the globe, (viii) fundoscopy and lastly (ix) corneal and palpebral fissure measurements (Fig. 2).

\section{Ocular inspection}

A total of 36 eyes, from 18 healthy adult aoudads were selected and used in this investigation. The anterior ocular structures were evaluated using a Finoff transilluminator (3.5 V halogen fiber optic, Welch Allyn, Skaneateles Falls, NY, USA) and a slit lamp biomicroscope (Hawk Eye; Dioptrix, L'Union, France). The funduses were evaluated using an indirect ophthalmoscope (Heine Omega 180 Headworn Binocular Indirect Ophthalmoscope, Dover, NH) and photographed with a 7.2 megapixel reflex digital camera with a Carl ZeissTM lens and 12x of optical zoom (DSC-H5; Sony ${ }^{\mathrm{TM}}$, Minato, Tokyo, Japan) (Fig. 3a).

\section{Schirmer tear test}

Sterile standardized STT strips (Schering Plough Animal Health, Union, NJ, USA) were used to perform the Schirmer type I test (Fig. 2a), which measures the basal plus a portion of the reflex tear production.

\section{Microbiological analysis}

For the microbiological analysis, samples were obtained by carefully touching the conjunctival sac and ocular surface (cornea and bulbar conjunctiva) with a sterile cotton swab (Fig. 2e). No topical anesthetic was

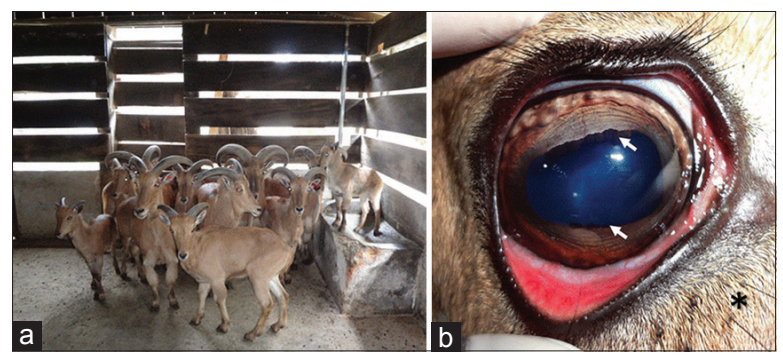

Fig. 1. (a) Part of the group of aoudads (Ammotragus lervia) from Curitiba's Zoo investigated in this study. The picture shows a mixed-aged group but only the adult animals were investigated. (b) A representative example of the general external appearance of the eye of the aoudad. True cilia (longer and thicker at the upper eyelid) are visible. Below the lower eyelid margin are two rows of sparsely distributed longer hairs (asterisk). Note in the anterior uvea the extensive iris collarette and the presence of an upper and a lower (more discrete) corpora nigra (arrows). The pupillary aperture shape was oval with the long axis horizontal. The limbus is relatively large and heavily pigmented. 

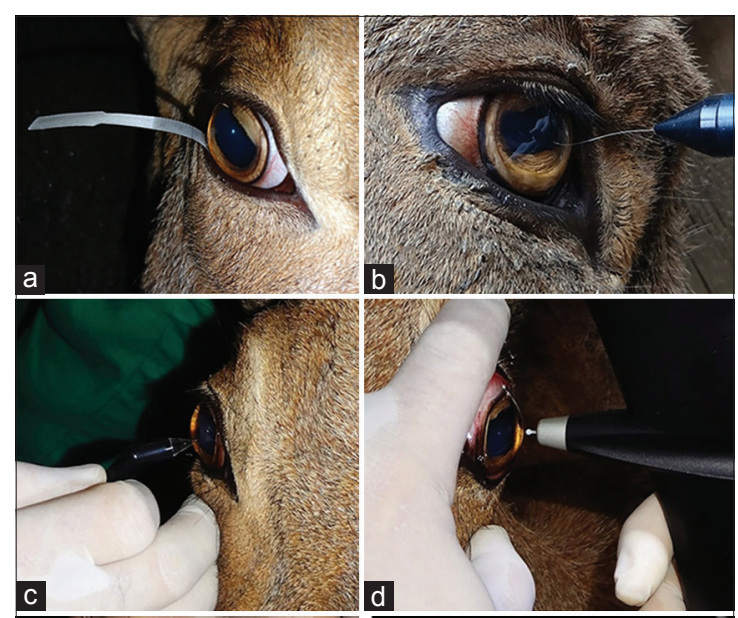

c
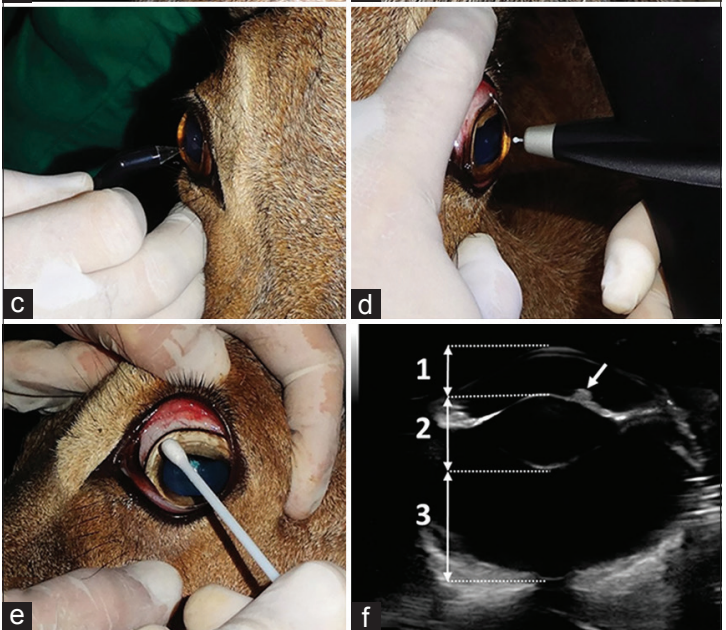

Fig. 2. Photographs of selected ocular tests performed in aoudads. (a) Schirmer tear test; (b) Esthesiometric analysis of central cornea; (c) Corneal pachymetry; (d) Rebound tonometry; (e) Swabbing the conjunctiva and eyelid margins; and (f) B-mode ocular echobiometry. Besides the globe axial length, the following echobiometric measurements were taken, 1- Anterior chamber depth (axial anterior chamber length); 2- Lens thickness (axial lens length); 3- Vitreous chamber depth (axial vitreous chamber length). Note the superior corpora nigra (arrow).
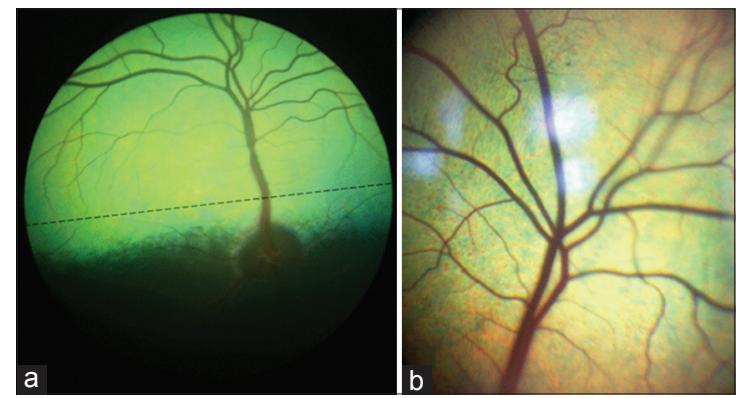

Fig. 3. Aoudad's fundoscopic appearance captured using TEFIT (a) and an indirect lens coupled with a slit lamp biomicroscope (Hawk Eye; Dioptrix, L'union, France). Note the extensive tapetum lucidum (a) the holangiotic retinal vascular pattern - (a) and (b). The tapetum has a granular or speckled appearance where stelullae of Winslow are present (b). The optic disc is grayish in color, oval in shape and located just inferior to the inferior border of the tapetum lucidum (a). The major blood vessels of the aoudad's retina radiate from the center of the optic nerve. (a) Blood vessels arising from the dorsal and ventral quadrants taper toward a region just above the inferior border of the tapetum lucidum. At this region no blood vessels are present and an imaginary line can be traced creating a streak where thin retinal blood vessels are rare or absent (a). used prior to sample collection as this may interfere with the growth of organisms (Mullin and Rubinfeld, 1997). Aerobic bacterial culture of the microorganisms was performed in BHI broth (brain-heart infusion), and on 5\% sheep blood agar and MacConkey plates, which were incubated at $37^{\circ} \mathrm{C}$ in an aerobic environment for 24-48 $\mathrm{h}$. The same bacterial growth media used in this research was also used elsewhere to establish normal conjunctival microbiota of the opossum, raccoon, ferret and chinchilla in other investigations (Pinard et al., 2002; Manca et al., 2006; Montiani-Ferreira et al., 2006, 2008b). Bacterial colonies were identified by Gram's stain and standard procedures.

\section{Corneal esthesiometry}

For the normal corneal sensitivity analysis, all aoudads were manually restrained, and a Cochet-Bonnet esthesiometer (Luneau Ophtalmologie, Chartres Cedex, France) was used (Fig. 2b). This instrument contains an adjustable nylon filament with a defined diameter, length and surface $(0.12 \mathrm{~mm}$ diameter, $60 \mathrm{~mm}$ length, and $0.0113 \mathrm{~mm}^{2}$ surface), which was applied at different lengths to the center of the cornea. A stimulus produced by the instrument's nylon monofilament that reaches the corneal touch threshold induces a corneal reflex, consisting of prompt eyelid closure, and discrete retraction of the globe. In this study only the center of the cornea was analyzed for corneal touch threshold, which was repeated five times using the same length of the nylon filament. The length of the nylon filament was then decreased at 5-mm increments until each aoudad responded with a corneal blink reflex. The corneal touch threshold was then quantified in millimeters length of the filament necessary to cause a blink reflex. The length of the filament, indicating a corresponding pressure at which the corneal blink reflex was positive, was deemed the central corneal sensitivity or central corneal touch threshold.

\section{Intraocular pressure}

Intraocular pressure (IOP) was measured in 36 eyes, using a veterinary rebound tonometer (Tonovet, Veterinary Division of $\mathrm{S} \& \mathrm{~V}$ Technologies AG, Henningsdorf, Germany) (Fig. 2d) with the P setting, which was a preset for other animals except dogs and horses. Six measurements were taken and averaged by the tonometer's internal software.

\section{Central corneal thickness}

Central corneal thickness (CCT) measurements were taken after the instillation of sterile topical anesthetic (proparacaine hydrochloride $0.5 \%$ ophthalmic solution USP; Alcon Laboratories, Forth Worth, TX, USA). CCT was measured using an ultrasonic pachymeter (Model 200P+; Micropach, Sonomed, Lake Success,NY, USA), with the speed of sound in the cornea preset at $1640 \mathrm{~m} / \mathrm{s}$ (Fig. 2c).

\section{B-mode ultrasonographic biometry}

B-mode scan ultrasonography was performed using 
a Sonix SP High Performance B-mode System (Ultrasonix, Richmond, BC, Canada). A drop of topical local anesthetic $(0.5 \%$ proxymetacaine chlorohydrate, Anestalcon ${ }^{\circledR}$, Alcon Laboratórios do Brasil, São Paulo, SP, Brazil) was instilled on each eye before ultrasonography. The B-scan 14-MHz probe was gently placed on the corneal surface perpendicular to the center of the cornea using ultrasonic transmission gel (Aquasonic-100; Parker Laboratories Inc., Fairfield, NJ, USA). Care was taken during probe placement to avoid corneal indentation. Reflected ultrasonic waves were captured. Optimal positioning was confirmed when the posterior wall of the eye globe could be clearly visualized on the B-scan ultrasonogram and the image appeared symmetrical and the reflections from the four principal landmarks (cornea, anterior lens surface, posterior lens surface and retinal surface) along the optic axis were perpendicular. The optimal image was frozen on the screen and then all echobiometric measurements were taken (Fig. 2f).

\section{Fundoscopy}

After B-mode ultrasonographic biometry the aoudads' eyes were gently rinsed twice with $0.9 \%$ saline solution in order to remove the ultrasonic transmission gel. Subsequently the aoudad's funduses were examined using an indirect ophthalmoscope (Heine Omega 180 Headworn Binocular Indirect Ophthalmoscope, Dover, $\mathrm{NH})$ and photographed using the topical endoscopy fundus imaging technique (TEFIT) (Fig. 3a) or a slit lamp containing a built-in indirect ophthalmoscopy lens (Digital 1.0x Imaging Lens, Hawk Eye, Dioptrix, L'Union, France) (Fig. 3b). For the TEFIT procedure a rigid, 8 -mm-diameter laparoscope with a 0 degree angle and a crescent-shape illumination tip (WeckTM, Pilling Weck, Markham, ON, Canada) was used. Both the rigid arthroscopy probe and the rigid laparoscope were connected to an adapter of a 7.2 megapixel reflex digital camera with a Carl ZeissTM lens and $12 \mathrm{x}$ of optical zoom (the same previously cited). The light source was a $175 \mathrm{~W}$ xenon lamp (Karl StorzTM, Tuttlingen, Germany) linked to the arthroscopy probe and the rigid laparoscope by a flexible fiber optic cable. Pupillary dilation for fundoscopy and fundus photography was performed following instillation of the following eyedrops, tropicamide $1 \%$ and phenylephrine $10 \%$ (Frumtost, São Paulo, SP, Brazil) one drop of each in each eye, with approximate 3-min intervals, every 10 min three times.

\section{Corneal and palpebral fissure biometry}

Palpebral fissure length, vertical and horizontal corneal diameters were measured using a stainless steel caliper ruler with an LCD display and an accuracy of $\pm 0.02 \mathrm{~mm}$ (Neiko Tools, Klamath Falls, OR, USA).

\section{Statistical analyses}

The obtained data were submitted to a KolmogorovSmirnov Goodness-of-Fit Test. Unpaired $t$-tests were used for data comparison between, right and left eyes and males and females. $P$-values $<0.05$ were deemed significant. JMP (SAS Institute, Inc., Cary, NC, USA) software was used to perform both descriptive and inferential statistical analyses. Measurements are reported as mean \pm standard deviation (SD).

\section{Results}

All continuous numeric data obtained for all ophthalmic tests in the population used in this investigation were normally distributed according to the KolmogorovSmirnov Goodness-of-Fit Test. Table 1 contains the condensed results of the descriptive statistical analyses. Morphological features of the normal aoudad eye Ophthalmic examinations revealed that the normal anterior ocular structures in the aoudad include dorsal and ventral puncta. Additionally, aoudads possess true cilia (eyelashes) at the upper (Fig. 1b) and lower eyelid margins; with the lower cilia being thinner

Table 1. Results obtained for selected ophthalmic diagnostic tests and echobiometric findings for the aoudad (Ammotragus lervia) eye.

\begin{tabular}{llccc}
\hline Ophtalmic Test or Parameter & Unit & Mean & Standard Deviation & 95\% Confidence Interval \\
\hline Schirmer tear test & $\mathrm{mm} / \mathrm{min}$ & 27.22 & 3.6 & $26.04-28.4$ \\
Esthesiometry & $\mathrm{cm}$ & 1.3 & 0.4 & $1.18-1.43$ \\
Intraocular pressure & $\mathrm{mmHg}$ & 19.47 & 3.9 & $18.2-20.74$ \\
Central corneal thickness & $\mu \mathrm{m}$ & 630.07 & 20.67 & $623.32-636.82$ \\
Axial globe length & $\mathrm{mm}$ & 28.43 & 0.88 & $26.65-28.43$ \\
Anterior chamber depth & $\mathrm{mm}$ & 9.03 & 0.17 & $4.7-5.4$ \\
Lens thickness & $\mathrm{mm}$ & 14.1 & 0.33 & $8.73-10.06$ \\
Vitreous chamber depth & $\mathrm{mm}$ & 34.8 & 0.53 & $12.93-15.06$ \\
Palpebral fissure length & $\mathrm{mm}$ & 25.05 & 3.12 & $33.77-35.82$ \\
Corneal horizontal length & $\mathrm{mm}$ & 17.95 & 2.18 & $24.34-25.77$ \\
Corneal vertical length & $\mathrm{mm}$ & & 1.68 & $17.40-18.50$ \\
\hline
\end{tabular}


and more sparsely distributed. Aoudads have a third eyelid (nictitating membrane) which moves across the surface of the cornea from the nasal canthus to the temporal canthus. The leading edge of the third eyelid is pigmented. Above the upper eyelid margin and below the lower eyelid margins, two rows of modifiedsparsely distributed longer hairs, resembling vibrissae, also called "tactile hair", were found in all individuals (Fig. 1b). There were approximately 16 to 18 pairs located above and 6 to 8 pairs below the eye. The iris colors of individual animals varied from a yellowishbrown to a grayish-brown. The iris collarette showed no crypts of Fuchs visible, being somewhat flat (Fig. 1b). Corpora nigra were present at the ciliary margin (the peripheral border of the iris). The lower corpora nigra were considerably more discrete (Fig. 1b). The pupillary aperture shape was oval with the long axis being horizontal. The presence of corpora nigra makes the pupil gain a rectangular appearance when observed from a distance.

\section{Schirmer tear test (STT)}

No significant STT differences were determined between right and left eyes or between sexes. Mean STT results for both eyes was $27.22 \pm 3.6 \mathrm{~mm} / \mathrm{min}$.

\section{Microbiological analysis}

Bacteria were isolated in microbiological samples from 33 out of 36 eyes. Five different genera of grampositive bacteria species were identified. The genera of the isolates were, Corynebacterium, Micrococcus, Bacillus, Streptococcus and Staphylococcus sp. Four different genera of gram-negative bacteria were isolated. The genera of the isolates were, Escherichia, Acinetobacter, Enterobacter and Citrobacter sp. A single genus of bacteria was isolated from 11 eyes. Two genera of bacteria were isolated from 20 eyes. Three genera of bacteria were isolated from two eyes. Staphylococcus sp. were the most common bacteria isolated, being present in 13 eyes (prevalence of $36.1 \%$ ). Micrococcus sp. and Bacillus sp. were the second most common bacteria isolated, being present in 9 eyes each (prevalence of $25 \%$ ). Lastly, Corynebacterium sp. was present in 5 eyes (prevalence of $13.88 \%$ ).

\section{Corneal esthesiometry}

There were no significant differences between males and females or between left and right eyes. The mean central corneal sensitivity was $1.3 \pm 0.4 \mathrm{~cm}$.

\section{Intraocular pressure (IOP)}

The mean value for IOP was $19.47 \pm 3.9 \mathrm{mmHg}$. There was no significant difference in IOP between males and females and no significant differences between left and right eyes.

\section{Central corneal thickness (CCT)}

The mean CCT was $630.07 \pm 20.67 \mu \mathrm{m}$. There was no significant difference in CCT between males and females and no significant differences between left and right eyes.

\section{B-mode ultrasonographic biometry}

No significant biometric differences were determined between right and left eyes or between sexes. The mean axial globe length was $29.94 \pm 0.96 \mathrm{~mm}$. Mean anterior chamber depth (axial anterior chamber length) was $5.03 \pm 0.17 \mathrm{~mm}$. Mean lens thickness (axial length) was $9.4 \pm 0.33 \mathrm{~mm}$. Mean vitreous chamber depth (axial chamber length) was $14.1 \pm 0.53 \mathrm{~mm}$.

\section{Fundus examination and fundus photography}

As viewed by the ophthalmoscope, it was possible to observe that the aoudad retina possess an extensive tapetum lucidum usually of a greenish-yellow to a yellowish-green color with a typical holangiotic retinal vascular pattern (Fig. 3). The tapetum has a granular or speckled appearance (Fig. 3). The optic disc was oval in shape and located just inferior to the inferior border of the tapetum lucidum. The major blood vessels of the retina radiate from the center of the optic nerve (Fig. 3). Blood vessels arising from the dorsal and ventral quadrants taper toward a region just above the inferior border of the tapetum lucidum. At this region no blood vessels are present and an imaginary line can be traced creating a streak where retinal blood vessels are rare or absent (Fig. 3a).

\section{Corneal and palpebral biometry}

The transition between cornea and the sclera (limbus) is relatively large and heavily pigmented and appears as a dense thick band (Fig. 1b). Mean horizontal corneal diameter (or width) of both eyes was $25.05 \pm 2.18 \mathrm{~mm}$ and the mean vertical corneal diameter of both eyes was $17.95 \pm 1.68 \mathrm{~mm}$. The mean horizontal palpebral fissure length of both eyes was $34.8 \pm 3.12 \mathrm{~mm}$.

\section{Discussion}

This study established normal values and ranges of several ophthalmic tests and biometric measurements of the eyes of a group of clinically normal aoudads (Ammotragus lervia), which was previously unavailable in the scientific literature.

The eyes of the aoudad are relatively large for the size of its head and body, and are therefore prominent. For instance, Barbary sheep eyes are bigger than the ones of the normal goat or sheep and other wild same size animals belonging to the Order Artiodactyla. The eyelashes and eyelid vibrissae are long and add to the distinctive appearance. In other species already investigated, vibrissae are considered to be true sensory organs located in anatomical areas where protective reflexes are important such as around the eye, or where environmental light is limited (McGreevy, 2004). Aoudads have a fairly elongated head and their eyes are placed laterally and posteriorly. These features together are similar to the horse head morphology (McGreevy, 2004) and are probably evolutionary adaptations to prevent tall grass from obstructing the view when grazing in both species. The presence of an elongated horizontally oval pupil observed here in the aoudad but also in other ungulates 
such as horses (Murphy and Arkins, 2007), cows, sheep and goats (Walls, 1943) allows for wide lateral vision (Murphy and Arkins, 2007). This type of pupil alternatively called "rectangular" (Prince, 1956) is also present in the deer, camel and hyrax. Optical analyses show that this horizontal pupillary elongation expands the field of view horizontally allowing terrestrial prey animals to see objects near the ground both in front of and behind them (Sprague et al., 2013).

Another evolutionary adaptation found in the eye of the aoudad is the corpora nigra, which are pigmented projections found on the upper and lower margins of the pupillary aperture. This anatomic structure already described in ungulates (Walls, 1943) is known to have many functions including contribution to pupillary constriction, prevention of actinic damage during grazing and possibly functions as an anti-glare device (Davidson, 1991). In the eye of the aoudad the upper corpora nigra is considerably larger than the lower ones. The authors believe that this feature accentuates information from the inferior visual field (Davidson, 1991).

The horizontal palpebral fissure length of the aoudad (34.8 $\mathrm{mm}$ ) is only a bit smaller than that of the cow $(44.4 \mathrm{~mm})$ and that of the horse $(39.5 \mathrm{~mm})$ (Wieser et al., 2013), which are both larger and heavier animals. It is however, considerably bigger than that reported for animals with similar sizes and weight such as the sheep (27.0 mm), goat (28.8 mm) (Wieser et al., 2013), dwarf goat $(21.6 \mathrm{~mm})$ (Olopade and Onwuka, 2004) and the Red Sokoto goat $(25.0 \mathrm{~mm})$ (Olopade and Onwuka, 2003). The cornea also follows this same trend and can be considered absolutely and relatively large. Its curvature was not evaluated but its external appearance is very prominent. Like in other ungulates the horizontal (transverse) corneal width is invariably considerably larger than the height (Henderson, 1950; Grinninger et al., 2010). The width and height were similar to the ones reported for the miniature horse, which were $25.8 \mathrm{~mm}$ and $19.4 \mathrm{~mm}$ respectively (Plummer et al., 2003).

The greenish tapetum lucidum observed is similar to the typical fibrosum type found in cow, sheep, goat and horse (Ollivier et al., 2004). The dark specks visible in the tapetal fundus of all aoudads investigates are identical to previously describe structures called "Stars of Winslow" (stelullae of Winslow) in other ungulates such as sheep, goats and horses. These structures represent deep choroidal vessel communications with other blood vessels from the choriocapillaris layer and the specks are the sites of tapetal penetration (Galán et al., 2006). The presence of this normal anatomic feature was not previously described in aoudads.

The linear avascular region in the aoudad fundus presumably represents a retinal specialization called a 'visual streak', which is similar to the macula in humans and the area centralis in dogs and cats, where an increased density of retinal neurons affords higher visual acuity. Early ophthalmoscopic observations of visual streaks reported a band-like thickening across the retina (Chievitz, 1889, 1891; Slonaker, 1897), which has since been shown by microscopic examination to be a high density of retinal ganglion cells. Although further histologic characterization is required to be able to define a visual streak in the aoudad, it is likely that the fundic morphology described in the aoudad fundus represents a visual streak considering the presence of a streak in other previously studied ungulates: cattle (Hebel, 1976), sheep (Hebel, 1976; Shinozaki et al., 2010), goats (Hughes and Whitteridge, 1973; GonzalezSoriano et al., 1997), giraffes (Coimbra et al., 2013), black rhinoceros (Pettigrew and Manger, 2008). The visual streak is not unique to ungulates. It has been found in other taxa including reptiles e.g. American garter snake (Wong, 1989), several species of birds e.g. Canada goose (Fernández-Juricic et al., 2011), ostrich (Boire et al., 2001), manx shearwater (Hayes et al., 1991), over 30 species of fish, and many other non-ungulate mammals including carnivores (spotted hyena Crocuta crocuta (Calderone et al., 2003)), aquatic mammals (common dolphin (Dral, 1983)), and marsupials (scrub wallaby (Tancred, 1981)). The visual streak determines visual acuity in a particular part of the visual field and its presence may have ecological correlations with habitat-type, anti-predator behaviors, and orientation behaviors (Johnson, 1901; Pumphrey, 1948; Luck, 1965; Hughes, 1977; Fernández-Juricic et al., 2011). The visual streak has been described to provide panoramic vision (Johnson, 1901; Vincent, 1912; Collin, 1999), and in combination with laterally placed eyes reduces the size of the blind area and offers a wide field of visual coverage (Hughes, 1977; Fernández-Juricic et al., 2011) thus reducing the need to sample visually by moving the eyes or head (Collin, 1999). Combined with the oval-shaped pupillary aperture, a visual streak in the aoudad would likely greatly enhance vision in the horizontal plane.

The STT is considered the gold standard test used to diagnose keratoconjunctivitis sicca (KCS) in domestic and wild animals. It is therefore important to perform a STT in all aoudads with ocular disease to rule out $\mathrm{KCS}$ as a cause of chronic eye disease such as corneal ulcers, conjunctivitis, keratitis and ocular discharge (Brooks, 2010; Trbolova et al., 2012). Although there has been no report of KCS in aoudads to date, it likely occurs in the species as it is a common ocular disease in most animals and human beings. It may be that the disease is underreported in aoudads due to the lack of knowledge of normal values for this test. When comparing STT values found in available studies of other species of ruminants, STT results in aoudads are quite high, similar but even higher to those reported for 
sheep (26.40 $\pm 17.70 \mathrm{~mm} / \mathrm{min})$ (Wieser et al., 2013), llamas (17.3 $\pm 1.1 \mathrm{~mm} / \mathrm{min})$ (Trbolova et al., 2012), goats (14.50 $\pm 3.78 \mathrm{~mm} / \mathrm{min})$ (Wieser et al., 2013), and pigmy goats $(15.8 \pm 5.7 \mathrm{~mm} / \mathrm{min})$ (Broadwater et al., 2007). Normal STT results obtained for the Barbary sheep $(27.22 \pm 3.6)$ are quite high comparing to other caprids (subfamily Caprinae) and other species of Artiodactyla. It is significantly higher than the one from llamas $(\mathrm{P}=0.0001)$, goats $(\mathrm{P}=0.0001)$ and pigmy goats $(\mathrm{P}=0.001)$. The observed STT mean value in Barbery sheep is higher than the one from sheep, however, due to the large variation reported for the sheep STT $(\mathrm{SD}=17.70)$ (Wieser et al., 2013), the analysis showed that the difference is not statistically significantly.

Normal conjunctival bacterial microbiota has been studied in several wild mammals such as the opossum (Pinard et al., 2002), bison (Davidson et al., 1999), deer (Dubay et al., 2000), and elephant (Tuntivanich et al., 2002). In the vast majority of these reports, gram-positive bacteria were the most common isolates and the present report is no exception. Both pathogenic and nonpathogenic bacteria were found in this investigation. Escherichia coli, Enterobacter sp and Citrobacter sp were isolated from the eyes of aoudads in this study. The presence of these gramnegative bacteria suggests possible eye contamination with fecal material and/or may represent a transient agent of the conjunctiva. Nonetheless, Escherichia coli was also isolated from normal conjunctival microbiota of dogs (Prado et al., 2005; Wang et al., 2008) and horses (Pisani et al., 1997; Andrew et al., 2003). Enterobacter sp and Citrobacter sp were isolated from the conjunctiva of clinically normal eyes of horses and human beings working as health professionals in a hospital environment (Pisani et al., 1997; Trindade et al., 2000). Additional studies are still necessary to try to determine whether or not some of these gramnegative bacteria are normal inhabitants of the aoudad's ocular microbiota. The label pathogenic versus nonpathogenic is misleading because it is known that in some cases of bacterial conjunctivitis, a formerly nonpathogenic conjunctival bacterium can overgrow and cause an imbalance of the ocular surface microbiota population, becoming pathogenic (Samuelson, 1999). The Cochet-Bonnet esthesiometer estimates the degree of sensitivity of the cornea by evaluating the corneal touch threshold (Chan-Ling, 1989; Barrett et al., 1991). The mean corneal touch threshold obtained in this investigation was similar to that of the foal $(1.4 \mathrm{~cm})$ (Brooks et al., 2000), chinchilla $(1.24 \mathrm{~cm})$ (Lima et al., 2010), Guinea pig (1.35 cm) (Wieser et al., 2013) and rabbit $(1.47 \mathrm{~cm})$ (Wieser et al., 2013), demonstrating that aoudads possess a less sensitive cornea compared to other species such as the adult horse, cat and cow (Wieser et al., 2013). These results should be interpreted with caution because of the well-known low precision of the Cochet-Bonnet esthesiometer in the 0.5 - to $2.0-\mathrm{cm}$ filament length range (Wieser et al., 2013). The aoudad's corneal sensitivity encountered in this investigation was exactly within that range. The pressure applied to the surface of the cornea by the examiner also can vary. It is known that these parameters affect this test results significantly (Boberg-Ans, 1956). In the present study, the temperature and humidity were not assessed in order to be able to correct the corneal sensitivity measurements with the nylon filament. Unfortunately, no formula or correction table exists at this time for the nylon filament currently used and the temperature or humidity conditions, which imposes a challenge for extrapolating corneal sensitivity data obtained with the Cochet-Bonnet esthesiometer. In light of all these possible variables and interferences produced by the examiner, some authors claim that a new esthesiometer, which can display the pressure applied to the surface of the cornea, should be created in order to make the measurement of the CTT more sensitive and comparisons between investigations more precise. Additionally, it might be worth considering a non-contact esthesiometer, since comparing to the Cochet-Bonnet esthesiometer the former allows for superior stimulus reproducibility and better control over stimulus characteristics, in addition to the ability for exploration of the response of all different types of neuro-receptors on the ocular surface (Golebiowski et al., 2011).

Tonometry is a fundamental part of a complete ophthalmic evaluation in any animal species. The main value of tonometry lies in the ability to detect pressure increases as an important clinical sign of glaucoma. However, a normal range of values for each species needs to be established. IOP measurements in the aoudads using the rebound tonometer resulted in means and ranges that were slightly higher than those reported for most other wild and domestic ungulates (Ofri et al., 2000, 2001; Willis et al., 2000). For instance, normal reported mean IOP for sheep was $16.36 \pm 2.19 \mathrm{mmHg}$ (Pigatto et al., 2011), which was significantly lower $(\mathrm{P}=0.0018)$ than that found in the aoudad $(19.47 \pm$ $3.9 \mathrm{mmHg}$ ). The aoudad's IOP seems to be similar to other ungulates with higher IOP such as the zebra (Ofri et al., 1998) and dairy cattle (Gum et al., 1998). However, comparison is difficult since most of the normal ranges for IOP previously reported in ungulates were obtained with applanation tonometers, and some even with indentation tonometry (Ofri et al., 1998). Before comparing and extrapolating IOP data from one study to others, researchers need to make sure the tonometry method was the same. It was shown that the Tonovet rebound tonometer may significantly overestimate the IOP values compared to the applanation tonometer, at least in one study using normal Eurasian eagle owls (Jeong et al., 2007). Another study conversely showed 
that results for the TonoVet-D calibration are similar to those obtained for dogs (Knollinger et al., 2005). Even though the rebound tonometer is tolerated well by most animal species because of its rapid and minimal stressinducing method, another factor to be considered when establishing IOP in wild and exotic species is stress. It is known that IOP values increase if the animal is firmly restrained, particularly in wild animal species (Jeong et al., 2007). All animals examined in this study were physically restrained and thus it is possible that stress could have influenced our results, though care was taken to avoid neck pressure.

Ultrasonic corneal pachymetry is an accurate and reliable in vivo method to measure corneal thickness in animals and human beings (Korah et al., 2000). It was shown that ultrasonic pachymetry set at a standard velocity of $1636 \mathrm{~m} / \mathrm{s}$ overestimates CCT as compared to optical coherence tomography (Alario and Pirie, 2014). However, correlation between the two mentioned modalities is excellent. Mean central corneal thickness (CCT) acquired with an ultrasonic pachymeter has been the subject of a number of reports investigating the cornea of human beings (Korah et al., 2000), several domestic (Stapleton and Peiffer, 1979; Gilger et al., 1991, 1998), exotic and wild animals (MontianiFerreira et al., 2006, 2008a, 2008b; Lima et al., 2010). In our investigation, mean CCT of the aoudad was not significantly different between males and females. The aoudad CCT is slightly thicker than adult dogs (598.54 $\mu \mathrm{m})$ (Alario and Pirie, 2014) and slightly thinner than the horse $(785.60 \mu \mathrm{m})$ (Plummer et al., 2003). It is similar to that of adult Saanen goats using a highresolution $20-\mathrm{MHz} \mathrm{A}-$ and B-mode ultrasonography transducer (Ribeiro et al., 2009).

Echobiometric data of the globe obtained using A- and B-mode ultrasonography were reported in children (Kurtz et al., 2004) several domestic (Schiffer et al., 1982; Rogers et al., 1986; Cottrill et al., 1989; Gilger et al., 1998; Tuntivanich et al., 2002; Plummer et al., 2003; Ribeiro et al., 2009), exotic and wild mammal species (Fernandes et al., 2003; Hernández-Guerra et al., 2007; Montiani-Ferreira et al., 2008a; Lima et al., 2010; Ruiz et al., 2015). The aoudad's axial globe length, lens thickness, and chamber depths were not significantly different according to the eye (left or right) studied or gender. This lack of difference was also observed in dog eyes and eyes of most other wild and exotic animals studied using B-mode ultrasonography. The eye of the aoudad is large in both ways, absolutely and relative to its body size. The axial globe length found for adult aoudads is larger than that obtained in other large mammals including cadaveric eyes of Ramboullet sheep (El-maghrabmy et al., 1995), Ile de France Sheep (Brandão et al., 2004) and Saneen goats (Ribeiro et al., 2009). The dimension of the internal structures such as anterior chamber depth, lens thickness and vitreous chamber depth follow the same pattern, being all comparable but larger than the sheep (Brandão et al., 2004) and goat (Ribeiro et al., 2009). Only the bovine (Potter et al., 2008), buffalo (Bos bubalis) (Kassab, 2012; Assadnassab and Fartashvan, 2013) and the dromedary eye (Osuobeni and Hamidzada, 1999; Kassab, 2012) demonstrated similar echobiometric dimensions, with equivalent lens thickness and vitreous chamber depth even though these are considerable larger ungulates in terms of body size.

In conclusion, this study provides novel data for normal values and reference ranges for several ophthalmic tests and ocular biometric parameters in healthy aoudads. The eyes are large and laterally placed in the head with several anatomic features that are likely evolutionary adaptations for grazing, which was also previously observed in other prey species of ungulates, such as horses, sheep and cattle.

Often a complete ocular examination of zoo animals is not routinely performed (Townsend, 2010) due to limitations such as lack of appropriate instruments (ophthalmoscopes, tonometers), disposable diagnostic test material (such as STT strips, fluorescein strips and eyedrops) and proper facilities (safe, large dark rooms). Nevertheless, the results of this study may assist veterinarians and veterinary ophthalmologists in the diagnosis of ocular diseases in aoudads.

\section{Acknowledgements}

The authors wish to thank Gillian Shaw for her help in the preparation of this manuscript.

\section{Conflict of interest}

The authors declare that there is no conflict of interest.

\section{References}

Abáigar, T., Domené, M.A. and Cassinello, J. 2012. Characterization of the estrous cycle and reproductive traits of the aoudad (Ammotragus lervia) in captivity. Theriogenology 77, 1759-1766.

Alados, C. and Shackleton, D.M. 1997. Regional Summary. In, Shackleton, D.M. Wild Sheep and Goats and Their Relatives, Status Survey and Conservation Action Plan for Caprinae. Gland, Switzerland, IUCN, pp: 47-48.

Alario, A.F. and Pirie, C.G. 2014. Central corneal thickness measurements in normal dogs, a comparison between ultrasound pachymetry and optical coherence tomography. Vet. Ophthalmol. 17, 207-211.

Andrew, S.E., Nguyen, A., Jones, G.L. and Brooks, D.E. 2003. Seasonal effects on the aerobic bacterial and fungal conjunctival flora of normal thoroughbred brood mares in Florida. Vet. Ophthalmol. 6, 45-50.

Assadnassab, G. and Fartashvan, M. 2013. Ultrasonographic evaluation of buffalo eyes. Turk. J. Vet. Anim. Sci. 37, 395-39. 
Barrett, P.M., Scagliotti, R.H., Merideth, R.E., Jackson, P.A. and Alarcon, F. 1991. Absolute corneal sensitivity and corneal trigeminal nerve anatomy in normal dogs. Vet. Comp. Ophthalmol. 1, 245-254.

Boberg-Ans, J. 1956. On the corneal sensitivity. Acta Ophthalmol. 34, 149-162.

Boire, D., Dufour, J.S., Theoret, H. and Ptito, M. 2001. Quantatative analysis of the retinal ganglion cell layer in the ostrich, Struthio Camelus. Brain Behav. Evol. 58, 343-355.

Brandão, C.V.S., Chiurciu, J.L.V., Ranzani, J.J.T., Mamprim, M.J., Zanini, M., Rodrigues, G.N., Cremonini, D.N., Lima, L.S.A., Peixoto, T.P., Marinho, L.F.L.P. and Teixeira, C.R. 2004. Comparação entre ultra-sonografia modo-A, modo-B e medidas diretas em olhos de ovinos. Braz. J. Vet. Res. Anim. Sci. 41, 68-69.

Brenner, D.J., Stokking, L., Donovan, T.A. and Lamberski, N. 2009. Pemphigus foliaceus in a barbary sheep (Ammotragus lervia). Vet. Rec. 165, 509-510.

Broadwater, J.J., Schorling, J.J., Herring, I.P. and Pickett, J.P. 2007. Ophthalmic examination findings in adult pygmy goats (Capra hicus). Vet. Ophthalmol. 10, 269-273.

Brooks, D.E., Clark, C.K. and Lester, G.D. 2000. Cochet-Bonnet aesthesiometer-determined corneal sensitivity in neonatal foals and adult horses. Vet. Ophthalmol. 3, 133-137.

Brooks, D.E. 2010. Ocular diseases, In, Taylor F.G.R., Brazil T., Hillyer M.H. (Ed.), Diagnostic Techniques in Equine Medicine. 2 ${ }^{\text {nd }}$ ed. Elsevier Limited, Amsterdam, pp: 305-322.

Calderone, J.B., Reese, B.E. and Jacobs, G.H. 2003. Topography of photoreceptors and retinal ganglion cells in the spotted hyena (Crocuta crocuta). Brain Behav. Evol. 62, 182-192.

Candela, M.G., Serrano, E., Martinez-Carrasco, C., Martín-Atance, P., Cubero, M.J., Alonso, F. and Leon, L. 2009. Coinfection is an important factor in epidemiological studies, the first serosurvey of the aoudad (Ammotragus lervia). Eur. J. Clin. Microbiol. Infect. Dis. 28,481-489.

Cassinello, J., Cuzin, F., Jdeidi, T., Masseti, M., Nader, I. and de Smet, K. 2008. Ammotragus lervia. The IUCN Red List of Threatened Species. Version 2014.3. <www.iucnredlist.org>. Downloaded on 12 January 2015.

Cassinello, J., Serrano, E., Calabuig, G. and Pérez, J.M. 2004. Range expansion of an exotic ungulate (Ammotragus lervia) in southern Spain, Ecological and conservation concerns. Biodivers. Conserv. 13, 851-866.

Cassinello, J. 1998. Ammotragus lervia, a review on systematics, biology, ecology and distribution. Ann. Zool. Fenn. 35, 149-162.

Chan-Ling, T. 1989. Sensitivity and neural organization of the cat cornea. Vet. Comp. Ophthalmol. 30, 1075-1082.

Chievitz, J.H. 1889. Untersuchungen über die Area centralis retinae. Arch Anat Physiol Anat Abt Suppl. 139-194.

Chievitz, J.H. 1891. Ueber das Vorkommen der area centralis retinae in den höheren Wirbetierklassen. R. Anat. Entwichlingsgesch. Suppl. 139, 311-334.

Cho, H.S., Shin, S.S. and Park, N.Y. 2006. Balantidiasis in the gastric lymph nodes of Barbary sheep (Ammotragus lervia), an incidental finding. J. Vet. Sci. 7, 207-209.

Coimbra, J.P., Hart, N.S., Collin, S.P. and Manger, P.R. 2013. Scene from above, retinal topography and spatial resolving power in the giraffe (Giraffa camelopardalis). J. Comp. Neurol. 521, 2042-2057.

Collin, S.P. 1999. Behavioural ecology and retinal cell topography. In Adaptive Mechanisms in the Ecology of Vision. Eds., Archer, S., Djamgoz, M.B., Loew, E. Partridge, J.C. and Vallerga, S. Kluwer Academic Publishers, Dordrecht, pp: 509-535.

Cottrill, N.B., Banks, W.J. and Pechman, R.D. 1989. Ultrasonographic and biometric evaluation of the eye and orbit of dogs. Am. J. Vet. Res. 50, 898-903.

Crenshaw, C.C., Martin, L.M., Mains C.R., Wright, R.D., Dart, M.G., Perkins, R.M., Purdy, P.H. and Ericsson, S.A. 2000. The use of buck and ram extenders and two packaging systems to cryopreserve aoudad (Ammotragus lervia) spermatozoa. Theriogenology 54, 69-74.

Davidson, H.J., Vestweber, J.G., Brightman, A.H., Van Slyke, T.H., Cox, L.K. and Chengappa, M.M. 1999. Ophthalmic examination and conjunctival bacteriologic culture results from a herd of North American bison. J. Am. Vet. Med. Assoc. 215, 1142-1144.

Davidson, M.G. 1991. Equine ophthalmology. In, Gelatt, K.N. (Ed.), Veterinary Ophthalmology. $2^{\text {nd }}$ ed. Lea \& Febiger, Philadelphia, pp: 576-610.

Dral, A.D.G. 1983. The retinal ganglion cells of Delphinus delphis and their distibution. Aquat Mamm. 10, 57-68.

Dubay, S.A., Williams, E.S. and Mills, K. 2000. Bacteria and nematodes in the conjunctiva of mule deer from Wyoming and Utah. J. Wildl. Dis. 36, 783-787.

El-maghrabmy, H.M., Nyland, T.G. and Bellhorn, R.W. 1995. Ultrasonographic and biometric evaluation of sheep and cattle eyes. Vet. Radiol. Ultras. 36, 148-151.

Fernandes, A., Bradley, D.V., Tigges, M., Tigges, J. and Herndon, J.G. 2003. Ocular measurements throughout the adult life span of rhesus monkeys. Invest. Ophthalmol. Vis. Sci. 44, 2373-2380.

Fernández-Juricic, E., Moore, B.A., Doppler, M., Freeman, J., Blackwell, B.F., Lima, S.L. and 
DeVault, T.L. 2011. Testing the terrain hypothesis, Canada geese see their world laterally and obliquely. Brain Behav. Evol. 77, 147-158.

Galán, A., Martín-Suárez, E.M. and Molleda, J.M. 2006 Ophthalmoscopic characteristics in sheep and goats, comparative study. J. Vet. Med. A Physiol. Pathol. Clin. Med. 53, 205-208.

Ghaffari, M.S., Hajikhani, R., Sahebjam, F., Akbarein, H. and Golezardy, H. 2012. Intraocular pressure and Schirmer tear test results in clinically normal longeared hedgehogs (Hemiechinus auritus), reference values. Vet. Ophthalmol. 15, 206-209.

Gilger, B.C., Davidson, M.G. and Howard, P.B. 1998. Keratometry, ultrasonic biometry, and prediction of intraocular lens power in the feline eye. Am. J. Vet. Res. 59, 131-134.

Gilger, B.C., Whitley, R.D. and Mclaughlin, S.A. 1991. Canine corneal thickness measured by ultrasonic pachymetry. Am. J. Vet. Res. 10, 1570-1572.

Golebiowski, B., Papas, E. and Stapleton, F. 2011. Assessing the sensory function of the ocular surface: implications of use of a non-contact air jet aesthesiometer versus the Cochet-Bonnet aesthesiometer. Exp. Eye Res. 92, 408-413.

Gonzalez-Soriano, J., Mayayo-Vicente, S., MartinezSainz, P., Contreras-Rodriguez, J. and RodriguezVeiga, E. 1997. A quantitative study of ganglion cells in the goat retina. Anat. Histol. Embryol. 26, 39-44.

Grinninger, P., Skalicky, M. and Nell, B. 2010. Evaluation of healthy equine eyes by use of retinoscopy, keratometry, and ultrasonographic biometry. Am. J. Vet. Res. 71, 677-681.

Gum, G.G., Gelatt, K.N., Miller, D.N. and MacKay, E.O. 1998. Intraocular pressure in normal dairy cattle. Vet. Ophthalmol. 1, 159-161.

Hamon, M.H. and Heap, R.B. 1990. Progesterone and oestrogen concentrations in plasma of Barbary sheep (aoudad, Ammotragus lervia) compared with those of domestic sheep and goats during pregnancy. J. Reprod. Fertil. 90, 207-211.

Hayes, B., Martin, G.R. and Brooke, M.D.L. 1991. Novel area serving binocular vision in the retina of procellariiform seabirds. Brain Behav. Evol. 37, 79-84.

Hebel, R. 1976. Distribution of retinal ganglion cells in five mammalian species (pig, sheep, ox, horse, dog). Anat. Embryol. 150, 45-51.

Henderson, T. 1950. Principles of Ophthalmology. Heinemann Medical Books. London, UK.

Hernández-Guerra, A.M., Rodilla, V. and LópezMurcia, M.M. 2007. Ocular biometry in the adult anesthetized ferret (Mustela putorius furo). Vet. Ophthalmol. 10, 50-52.

Hilton-Taylor, C. 2000. IUCN Red List of Threatened Species. $1^{\text {st }}$ ed. IUCN, Gland, Switzerland.
Hughes, A. 1977. The topography of vision in mammals of contrasting life style, comparative optics and retinal organization. In, The visual system in vertebrates (Ed. by F. Crescitelli), New York, Springer-Verlag, pp: 615-756.

Hughes, A. and Whitteridge, D. 1973. Receptive Fields And Topographical Organization Of Goat Retinal Ganglion-Cells. Vision Res. 13, 1101-1114.

Jeong, M.B., Kim, Y.J., Yi, N.Y., Park, S.A., Kim, W.T., Kim, S.E., Chae, J.M., Kim, J.T., Lee, H. and Seo, K.M. 2007. Comparison of the rebound tonometer (TonoVet) with the applanation tonometer (TonoPen XL) in normal Eurasian Eagle owls (Bubo bubo). Vet. Ophthalmol. 10, 376-379.

Johnson, G.L. 1901. Contributions to the comparative anatomy of the mammalian eye chiefly based on ophthalmoscopic examination. Philos. T. R. Soc. B 194, 1-82.

Kassab, A. 2012. Ultrasonographic and macroscopic anatomy of the enucleated eyes of the buffalo (Bos bubalis) and the one-humped camel (Camelus dromedarius) of different ages. Anat. Histol. Embryol. 41, 7-11.

Kingdon, J. 1997. The Kingdon Field Guide to African Mammals. $1^{\text {st }}$ ed. Academic Press Ltd, London, pp: 496.

Knollinger, A.M., La Croix, N.C., Barrett, P.M. and Miller, P.E. 2005. Evaluation of a rebound tonometer for measuring intraocular pressure in dogs and horses. J. Am. Vet. Med. Assoc. 227, 244-248.

Korah, S., Thomas, R. and Muliyil, J. 2000. Comparison of optical and ultrasound pachymetry. Indian J. Ophthalmol. 48, 279-283.

Kudirkiene, E., Zilinskas, H. and Siugzdaite, J. 2006. Microbial flora of the dog eyes. Vet. Zootech-Lith 34, 18-21.

Kurtz, D., Manny, R. and Hussein, M. 2004. Variability of the ocular component measurements in children using A-scan ultrasonography. Optometry Vision Sci. 81, 35-43.

Lima, L., Montiani-Ferreira, F., Tramontin, M., Leigue dos Santos, L., Machado, M., Lange, R.R. and Russ, H. 2010. The chinchilla eye, morphologic observations, echobiometric findings and reference values for selected ophthalmic diagnostic tests. Vet. Ophthalmol. 13 Suppl. 14-25.

Luck, C.P. 1965. The comparative morphology of the eyes of certain African suiformes. Vision Res. 5, 283-297.

Manca, L., Pirastru, M., Mereu, P., Multineddu, C., Olianas, A., el Sherbini, el S., Franceschi, P., Pellegrini, M. and Masala, B. 2006. Barbary sheep (Ammotragus lervia), the structure of the adult beta-globin gene and the functional properties of its hemoglobin. Comp. Biochem. Physiol. B Biochem. Mol. Biol. 145, 214-219. 
Martins, B.C., Oriá, A.P., Souza, A.L., Campos, C.F., Almeida,D.E.,Duarte,R.A.,Soares,C.P.,Zuanon,J.A., Neto, C.B., Duarte, J.M., Schocken-Iturrino, R.P. and Laus, J.L. 2007. Ophthalmic patterns of captive brown brocket deer (Mazama gouazoubira). J. Zoo Wildl. Med. 38, 526-532.

Mayo, E., Ortiz, J., Martínez-Carrasco, C., Garijo, M.M., Espeso, G., Hervías, S. and Ruiz de Ybáñez, M.R. 2013. First description of gastrointestinal nematodes of Barbary sheep (Ammotragus lervia), the case of Camelostrongylus mentulatus as a paradigm of phylogenic and specific relationship between the parasite and its ancient host. Vet. Res. Commun. 37, 209-215.

McGreevy, P. 2004. Equine Behavior, A Guide for Veterinarians and Equine Scientists. $1^{\text {st }}$ ed. Saunders, Philadelphia.

McLelland, D.J., Kirkland, P.D., Rose, K.A., Dixon, R.J. and Smith, N. 2005. Serologic responses of Barbary sheep (Ammotragus lervia), Indian antelope (Antilope cervicapra), wallaroos (Macropus robustus), and chimpanzees (Pan troglodytes) to an inactivated encephalomyocarditis virus vaccine. J. Zoo Wildl. Med. 36, 69-73.

Mereu, P., Palici, di Suni M., Manca, L. and Masala, B. 2008. Complete nucleotide mtDNA sequence of Barbary sheep (Ammotragus lervia). DNA Seq. 19, 241-245.

Montiani-Ferreira, F., Mattos, B.C. and Russ, H.H. 2006. Reference values for selected ophthalmic diagnostic tests of the ferret (Mustela putorius furo). Vet. Ophthalmol. 9, 209-213.

Montiani-Ferreira, F., Shaw, G., Mattos, B.C., Russ, H.H. and Vilani, R.G. 2008a. Reference values for selected ophthalmic diagnostic tests of the capuchin monkey (Cebus apella). Vet. Ophthalmol. 3, 197-201.

Montiani-Ferreira, F., Truppel, J., Tramontin, M.H., Vilani, R.G. and Lange, R.R. 2008b. The capybara eye, clinical tests, anatomic and biometric features. Vet. Ophthalmol. 11, 386-394.

Morikawa, V.M., Zimpel, C.K., Paploski, I.A., Lara, Mdo, C., Villalobos, E.M., Romaldini, A.H., Okuda, L.H., Biondo, A.W. and Barros Filho, I.R. 2014. Occurrences of anti-Toxoplasma gondii and anti-Neospora caninum antibodies in Barbary sheep at Curitiba zoo, southern Brazil. Rev. Bras. Parasitol. Vet. 23, 255-259.

Mullin, G.S. and Rubinfeld, R.S. 1997. The antibacterial activity of topical anesthetics. Cornea 16, 662-665.

Münster, P., Fechner, K., Völkel, I., von Buchholz, A. and Czerny, C.P. 2013. Distribution of Mycobacterium avium ssp. paratuberculosis in a German zoological garden determined by IS900 semi-nested and quantitative real-time PCR. Vet. Microbiol. 163, 116-123.

Murphy, J. and Arkins, S. 2007. Equine learning behaviour. Behav. Processes 76, 1-13.

Ofri, R., Horowitz, I.H. and Kass, P.H. 1998. Tonometry in three herbivorous wildlife species. Vet. Ophthalmol. 1, 21-24.

Ofri, R., Horowitz, I.H. and Kass, P.H. 2000. How low can we get? Tonometry in the Thomson gazelle (Gazella thomsoni). J. Glaucoma 9, 187-189.

Ofri, R., Horowitz, I.H., Levison, M. and Kass, P.H. 2001. Intraocular pressure and tear production in captive eland and fallow deer. J. Zoo Wildl. Med. 37, 387-390.

Ollivier, F.J., Samuelson, D.A., Brooks, D.E., Lewis, P.A., Kallberg, M.E. and Komáromy, A.M. 2004. Comparative morphology of the tapetum lucidum (among selected species). Vet. Ophthalmol. 7, 11-22.

Olopade, J.O. and Onwuka, S.K. 2003. A preliminary investigation into some aspects of the craniofacial indices of the Red Sokoto (Maradi) goat in Nigeria. Folia Vet. 47, 57-59.

Olopade, J.O. and Onwuka, S.K. 2004. Morphometric studies of the cranio-facial region of the west african dwarf goat in Nigeria. Int. J. Morphol. 22, 145-148.

Osuobeni, E.P. and Hamidzada, W.A. 1999. Ultrasonographic determination of the dimensions of ocular components in enucleated eyes of the onehumped camel (Camelus dromedarius). Res. Vet. Sci. 67, 125-129.

Pence, D.B. and Gray, G.G. 1981. Elaeophorosis in Barbary sheep and mule deer from the Texas Panhandle. J. Wildl. Dis. 17, 49-56.

Pettigrew, J.D. and Manger, P.R. 2008. Retinal ganglion cell density of the black rhinoceros (Diceros bicornis), Calculating visual resolution. Visual Neurosci. 25, 215-220.

Pigatto, J.A.T.P., Pereira, F.Q., Albuquerque, L., Corrêa, L.F.D., Bercht, B.S., Hünning, P.S., Silva, A.A.R. and De Freitas, L.V.R.P. 2011. Intraocular pressure measurement in sheep using an applanation tonometer. Rev. Ceres 58, 685-689.

Pinard, C.L., Brightman, A.H., Yeary, T.J., Everson, T.D., Cox, L.K., Chengappa, M.M. and Davidson, H.J. 2002. Normal conjunctival flora in the North American opossum (Didelphis virginiana) and raccoon (Procyon lotor). J. Wildl. Dis. 38, 851-855.

Pirastru, M., Multineddu, C., Mereu, P., Sannai, M., El Sherbini, el S., Hadjisterkotis, E., Nàhlik, A., Franceschi, P., Manca, L. and Masala, B. 2009. The sequence and phylogenesis of the globin genes of Barbary sheep (Ammotragus lervia), goat (Capra hircus), European mouflon (Ovis aries musimon) and Cyprus mouflon (Ovis aries ophion). Comp. Biochem. Physiol. 4, 168-173.

Pisani, E.H.R., Barros, P.S.M. and Avila, F.A. 1997. Microbiota conjuntival normal de eqüinos. Braz. J. 
Vet. Res. Anim. Sci. 34, 261-265.

Plummer, C.E, Ramsey, D.T. and Hauptman, J.G. 2003. Assessment of corneal thickness, intraocular pressure, optical corneal diameter, and axial globe dimensions in Miniature horses. Am. J. Vet. Res. 64, 661-665.

Portas, T.J., Bryant, B.R., Jones, S.L., Humphreys, K., Gilpin, C.M. and Rose, K.A. 2009. Investigation and diagnosis of nontuberculous mycobacteriosis in a captive herd of aoudad (Ammotragus lervia). J. Zoo Wildl. Med. 40, 306-315.

Potter, T.J., Hallowell, G.D. and Bowen, I.M. 2008. Ultrasonographic anatomy of the bovine eye. Vet. Radiol. Ultras. 49, 172-175.

Prado, M.R., Rocha, M.F., Brito, E.H., Girão, M.D., Monteiro, A.J., Teixeira, M.F. and Sidrim, J.J. 2005. Survey of bacterial microorganisms in the conjuntival sac of clinically normal dogs and dogs with ulcerative keratitis in Fortaleza, Ceará, Brazil. Vet. Ophthalmol. 8, 33-37.

Prince, J.H. 1956. Comparative Anatomy of the Eye. Charles C Thomas, Springfield.

Pumphrey, R.J. 1948. The theory of the fovea. J. Exp. Biol. 25, 299-312.

Ribeiro, A.P., Silva, M.L., Rosa, J.P., Souza, S.F., Teixeira, I.A. and Laus, J.L. 2009. Ultrasonographic and echobiometric findings in the eyes of Saanen goats of different ages. Vet. Ophthalmol. 12, 313-317.

Rogers, M., Cartee, R.E., Miller, W. and Ibrahim, A.K. 1986. Evaluation of the extirpated equine eye using B-mode ultrasonography. Vet. Radiol. 27, 24-29.

Ruiz, T., Campos, W.N., Peres, T.P., Gonçalves, G.F., Ferraz, R.H., Néspoli, P.E., Sousa, V.R. and Ribeiro, A.P. 2015. Intraocular pressure, ultrasonographic and echobiometric findings of juvenile Yacare caiman (Caiman yacare) eye. Vet. Ophthalmol. 1, 40-45.

Samuelson, D.A. 1999. Ophthalmic anatomy. In, Gelatt, K. N. (Ed.), Veterinary Ophthalmology. $3^{\text {rd }}$ ed. Lippincott Williams and Wilkins, Philadelphia, pp: 31-50.

Santiago-Moreno, J., Castaño, C., Toledano-Díaz, A., Esteso, M.C., López-Sebastián, A., Guerra, R., Ruiz, M.J., Mendoza, N.,Luna, C., Cebrián-Pérez, J.A. and Hildebrandt, T.B. 2013. Cryopreservation of aoudad (Ammotragus lervia sahariensis) sperm obtained by transrectal ultrasound-guided massage of the accessory sex glands and electroejaculation. Theriogenology 79, 383-391.

Shinozaki, A., Hosaka, Y., Imagawa, T. and Uehara, M. 2010. Topography of ganglion cells and photoreceptors in the sheep retina. J. Comp. Neurol. 518, 2305-2315.

Slonaker, J.R. 1897. A comparative study of the area of acute vision in vertebrates. J. Morphol. 13, 445-494.

Sprague, W., Helft, Z., Parnell, J., Schmoll, J., Love, G. and Banks, M. 2013. Pupil shape is adaptive for many species. J. Vision. 13, 607.

Stapleton, S. and Peiffer, R. 1979. Specular microscopic observations of the clinically normal canine corneal endothelium. Am. J. Vet. Res. 40, 1803-1804.

Stuart, C. and Stuart, T. 1997. Field Guide to the Larger Mammals of Africa. $3^{\text {rd }}$ ed. Struik Publishers, Cape Town.

Tancred, E. 1981. The distribution and sizes of ganglion cells in the retinas of five Australian marsupials. J. Comp. Neurol. 196, 585-603.

Townsend, W.M. 2010. Examination techniques and therapeutic regimens for the ruminant and camelid eye. Vet. Clin. North Am. Food. Anim. 26, 437-458.

Trbolova, A., Gionfriddo, J.R. and Ghaffari, M.S. 2012. Results of Schirmer tear test in clinically normal llamas (Lama glama). Vet. Ophthalmol. 15, 383-385.

Trindade, R.C., Bonfim, A.C.R. and Resende, M.A. 2000. Conjunctival Microbial Flora of Clinically Normal Persons Who Work in a Hospital Environment. Braz. J. Microbiol. 31, 12-16.

Tuntivanich, P., Soontornvipart, K., Tuntivanich, N., Wongaumnuaykul, S. and Briksawan, P. 2002. Conjunctival microflora in clinically normal Asian elephants in Thailand. Vet. Res. Commun. 26, 251-254.

Vincent, S.B. 1912. The mammalian eye. J. Anim. Behav. 2, 249-255.

Wacher, T., Baha El Din, S., Mikhail, G. and Baha El Din, M. 2002. New observations of the "extinct" Aoudad Ammotragus lervia ornata in Egypt. Oryx 36, 301-304.

Walls, G.L. 1943. The vertebrate eye and its adaptive radiation. Michigan, The Cranbrook Press.

Wang, L., Pan, Q., Zhang, L., Xue, Q., Cui, J. and Qi, C. 2008. Investigation of bacterial microorganisms in the conjunctival sac of clinically normal dogs and dogs with ulcerative keratitis in Beijing, China. Vet. Ophthalmol. 11, 145-149.

Wieser, B., Tichy, A. and Nell, B. 2013. Correlation between corneal sensitivity and quantity of reflex tearing in cows, horses, goats, sheep, dogs, cats, rabbits, and guinea pigs. Vet. Ophthalmol. 16, 251-262.

Willis, A.M., Anderson, D.E., Gemensky, A.J., Wilkie, D.A. and Silveira, F. 2000. Evaluation of intraocular pressure in eyes of clinically normal llamas and alpacas. Am. J. Vet. Res. 61, 1542-1544.

Wong, R.O.L. 1989. Morphology and distribution of neurons in the retina of the American garter snake Thamnophis sirtalis. J. Comp. Neurol. 283, 587-601.

Yeruham, I., David, D., Brenner, J., Goshen, T. and Perl, S. 2004. Malignant catarrhal fever in a Barbary sheep (Ammotragus lervia). Vet. Rec. 155, 463-465. 